From September 9 to September 22, under Dr. Eric Pritchard's direction, a course in Diseases of Infants will take place at the Infants Hospital. These courses are most popular, judging from the demand for them, and especially suitable to those interested in infant welfare work. Visits to other centres will be made on several occasions in addition to the various clinics held at the hospital. Fee $£_{3} 3$ s.

From September Io to October $5 \mathrm{Dr}$. Porter Phillips and members of his staff will undertake a series of lecture-demonstrations in Psychological Medicine at the Bethlem Royal Hospital, on Tuesdays and Saturdays at I I a.m. Fee $£$ I Is.

Of interest to Panel Practitioners and others desiring a "brush-up," an intensive course in Medicine, Surgery and the Specialities will be held at the Westminster Hospital. The daily sessions will begin at ro.30 a.m. and will continue until 5.30 p.m., including both Saturdays (mornings only), when visits will be made to two mental institutions connected with the hospital. Fee $£ 3$ 3s., or $£ 2$ 2s. for either week.

From September 30 to October 4 a course in Gastro-enterology will be given at the Prince of Wales's General Hospital and the North Middlesex Hospital, Tottenham. Instruction will continue throughout the day, and both the medical and surgical aspect will be dealt with. Fee t 44 s.

We would remind readers that the special course in Cardiology at the National Hospital for Diseases of the Heart, to be held October 7 to October 18 , is limited to twenty entries, so that those desirous of gaining admission would be well advised to apply early for this particular course.

An experimental course, lasting all day, will be given by the members of the staff of the Metropolitan-Hospital, October 2 I to November 2, in medicine, surgery and the specialities. Fee $£ 33$ s.

Copies of all the syllabuses of the above courses can be obtained from the Fellowship of Medicine, I, Wimpole Street, W.r. For those interested in the M.R.C.P. Evening Course, particulars of which were given in our last issue, fixed for October I $4_{4}$ to December 6 and comprising sixteen lectures, on Tuesdays and Fridays at 8.30 p.m., at the Medical Society of London, r r, Chandos Street, W.I, we have been asked to state that the detailed syllabus is now available.

In addition to the M.R.C.P. special course of lectures, a series of lectures on "Common Complaints" will be given on successive Mondays at 5 o'clock, beginning October I4, at the Medical Society of London lecture hall. No fee for attendance.

The series of weekly demonstrations in medicine and surgery, also arranged by the Fellowship, will be resumed in October at the various hospitals, and these likewise will be free to the medical profession.

We would remind our readers that the Fellowship of Medicine provides also a General Course of instruction consisting of the clinical practice of its associated hospitals. A programme is provided setting the clinics out under subject headings, and holders of the tickets are free to make out their own time-table in accordance with their requirements and are entitled to attend any, or all, of the hospitals. Special arrangements are made for part-time study. Comprehensive tickets range from $£^{2} 2$ s. to $£^{2}$ I (one week to one year).

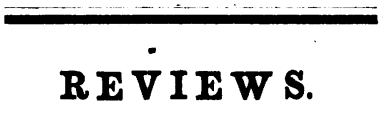

The Millennium and Medical Science. By David Nicholas Schaffer, M.D. Published by Wilbur Needham, Evanston, Ill., U.S.A.

This is not intended to be in any sense a textbook of medicine, but a series of essays written in language suitable for the reading of the non-medical person. There are three 
essays, entitled "Object Lessons in Health and Disease," "Nature's Work and Organ Transplantation," and "Science Triumphant and its True Practice." To criticize such a book from the medical standpoint is impossible, though there is much in the writing that is both interesting and instructive. From the philosophical standpoint it has many virtues, and it is well put together and the deductions reasonable. As to the wisdom or otherwise of the layman reading semimedical books, the writer would not care to express an opinion. Possibly, in the present day, when our friend G. B. S. takes upon himself to judge the practice of the medical profession in his delightful way, it may be well that medical secrecy should be shown to have no foundation other than on the purely scientific or technical side. With this remark we will leave the book to the judgment of its readers.

\section{A Graphic Guide to Elementary} SUkgery. By Prof. Dr. Th. Naegeli, Bunn. Translated by J. Snowman, M.D., M.R.C.P. John Bale, Sons and Danielsson, Ltd.

This book is intended for the use of students commencing their surgical studies. It deals entirely with general principles, which are very clearly and concisely stated. Obviously the statements in a book of this kind must be dogmatic, and no argument has been attempted. All the statements are illustrated profusely by diagrams. Indeed the illustrations are the great feature of this book. They are all of a diagrammatic nature and complete to the minutest detail. Some of them would appear to be almost unnecessarily so. One would hardly imagine it necessary to have shown a revolver in the act of being fired to illustrate a gun-shot wound of the intestine.

The illustrations are also coloured, so as to make their interpretation easy and distinct. The book would be an excellent one for nurses, as it is concerned largely with definitions which are fully explained by terms which are in constant use. In short we can thoroughly recommend this book as a very elementary preparatory study for those commencing surgery. Its great feature is its simplicity.

Medical Adventure. By Dr. Ernest Ward, F.R.C.S.Eng. John Bale, Sons and Danielsson, Limited.

This is a series of experiences gained in general practice and regarded from the point of view of the man who is engaged in general practice. We wish that more general practitioners would follow the example of Dr. Ernest Ward, and record their experiences and the conclusions come to in regard to them in the very interesting and instructive way that he has. One reads this book rather like a novel. In the description of incidents and, in many instances, the amusing way in which they are narrated, Dr. Ward is able to translate us into the actual surroundings of his various? visits, in which we seem to be making the same deductions, and in some instances the same mistakes that he has made and to which he has so ably and properly confessed. Perhaps some of the most interesting and instructive chapters are those on his legal experiences. The book is full of instructive material, and it is quite evident that during his very busy career Dr. Ward has kept full notes of all the most important cases.

In many ways the book is a remarkable one. It is very well illustrated, and we most heartily recommend it for perusal, not only by general practitioners, but also by consultants and anybody interested in the practice of medicine. 